\title{
Influence of Inter-Stop Transport Distances of a Freight Train upon Its Traction Energy Cost Intensities for Different Target Speeds
}

\author{
Xuesong Feng ${ }^{1, *}$, Yi Liu ${ }^{1}$, Quan Wang ${ }^{1}$, Haidong Liu ${ }^{1}$, Yong Ding ${ }^{1}$ and Qipeng Sun ${ }^{2}$ \\ ${ }^{1}$ MOE Key Laboratory for Urban Transportation Complex Systems Theory \& \\ Technology, Beijing Jiaotong University, No.3 Shangyuancun, Haidian District, \\ Beijing 100044, P.R. China \\ ${ }^{2}$ School of Economics and Management, Chang 'an University, Nan Er Huan Zhong \\ Duan, Xi'an 710064, China
}

\begin{abstract}
Based on train traction calculation theories, this research first simulates the transports of a typically formed freight train hauled by representative types of freight locomotives in China. Accordingly, the exact change of the traction energy cost intensity of the train in the effect of its inter-stop transport distance is analyzed in a quantificational way for different target speeds. It is found that the inter-stop transport distance of a freight train should be no shorter than 20.00 kilometers in order to decrease the traction energy cost per unit transport especially for a relatively high target speed. As a result, it is suggested that the railway freight transport work ought to try its best to utilize a heavy load train in view of its average inter-stop transport distance of the whole trip and its comparatively energy-saving target speeds. Furthermore, as for the transport operation of a railway network, the requirements to the time of each transport work of a train and so on should also be considered for its traction energy saving in an integrated manner.
\end{abstract}

Keywords: freight train, inter-stop transport distance, target speed, traction energy cost intensity, train traction calculation, computer-aided simulation

\section{Introduction}

Railway is one of the major freight transport modes in China. About $19.50 \%$ of the total $14,183.70$ billion freight ton-kilometers $(\mathrm{t}-\mathrm{km})$ in 2010 [1] are completed by freight trains in China. These freight trains consume much energy every day [2-4]. It is well known that the Traction Energy Cost (TEC) intensity of a train is much concerned with its target speed [5-8]. Many researchers have been continuously making effort to study their relationship [9-13] in view of the integrated impacts of multi-factors for the decrease of TEC. Exploring the most reasonable control strategies of a train is one of the important research direction. For instance, Kim and Chien $[14,15]$ make use of the simulated annealing algorithm to decide the control patterns of a train in its transport process in consideration of track alignments, speed limits

\footnotetext{
1 * Corresponding author. Tel. \& Fax.: +86-(0)10-51684208.

Email address: xsfeng@bjtu.edu.cn (Xuesong Feng).
} 
and transport schedule adherence for the minimal TEC. In contrast, some efforts to minimize the TEC of a train focus on its mass [16], stop frequency [17], out-put powers from different engines [18], formation scale [19], energy storage [20, 21], etc., In addition, many other works attempt to optimize the general TEC of multi-trains from a systematic viewpoint. For example, artificial neural networks, genetic algorithms and simulation approaches are used in integrated ways by Acikbas and Soylemez [22] and Yang et al., [23] to seek the coasting strategies of different trains on a rail network to minimize the overall TEC of all the trains. Valuable research findings from exemplifications have been in practice examined by previous studies. However, these findings still cannot truly clarify the detailed influence of the target speed of especially a (conventional locomotive-hauled) freight train upon its traction energy cost intensity from an adequately quantificational and integrated perspective.

Based on computer-aided simulations, this research first analyze the freight transports of a typically formed Chinese freight train hauled by respectively various types of representative freight locomotives in China on a hypothetically straight and smooth railway line. Accordingly, this study tries to explore the accurate comprehensive effect of the inter-stop transport distance (i.e., the length of stop-spacing) together with the target speed of the train on the intensity of its TEC in a quantificational way. Moreover, the traction performance of the applied locomotive of the train is also considered in this research. In fact, the effect of the transport distance between neighboring stops on the TEC of a train is also the reflection of the impact of the stop frequency of the whole trip of the train upon its energy cost intensity of train traction [16, 24]. The latter parts of this paper are organized as follows. The formation of the studied freight train in this research and the computer-aided simulation approach utilized in this work to compute the TEC of the train are explained in Section 2. Next, Section 3 studies the detailed changes of the TECs per 10,000 t-km of the train with the decrease of its inter-stop transport distance for different target speeds by utilizing the simulation approach interpreted in Section 2. Finally, Section 4 draws conclusions, makes some suggestions for the transport work of the freight trains and proposes some future research issues.

\section{Train Formation and Simulation Approach}

A typical freight train in China today is usually formed with 60 coupled wagons hauled by 1 locomotive. One of the major types of the wagons is the C70. 60 coupled and fully loaded C70 wagons hauled by 1 locomotive compose the freight train studied in this research. The weight, loading capacity and designed top-speed of the C70 wagon are respectively 23.60 tons $(\mathrm{t}), 70.00 \mathrm{t}$ and 120.00 kilometers per hour $(\mathrm{km} / \mathrm{h})$ [25]. Therefore, the total weight of the 60 wagons of the studied freight train whose loading capacities are 100\% utilized is 5,616.00 t. The transport processes of the studied freight train hauled by respectively two major types of the freight locomotives for the railway freight transport work in China, i.e., the (electric) SS1 and the (electric) SS4, are simulated in this research. The weights of the SS1 and the SS4 are $138.00 \mathrm{t}$ and $184.00 \mathrm{t}$ in a respective manner and their designed top-speeds are correspondingly $90.00 \mathrm{~km} / \mathrm{h}$ and $100.00 \mathrm{~km} / \mathrm{h} \mathrm{[26].}$

With referring to the study of Feng [27], the general framework of the computer-aided simulation approach according to train traction calculation theories [28, 29], as shown in Figure 1, is applied in this research to calculate the TEC of the transport of a train. The whole trip of the train from one stop to the next is simulated for one calculation interval after another. The lengths of all the calculation intervals are set to be 1.00 second (s) here. Only the traction force and operating condition (i.e., motoring, coasting or braking) of the train are considered to be unchanged in one calculation interval in this research. The train at a station is started up with its full traction power towards the target speed. With the first achievement 
of the target speed by the continuous acceleration of the train from its startup, the train commences to coast till the difference between its instant speed and the target speed reaches a constant value. Thereafter the train accelerates with its full traction power to the target speed alternately. In order to ensure the safe stop of the train at the next station, the train begins to decide whether taking brakes is necessary or not in a calculation interval when the train arrives at a rail site where there is a certain distance away from the next stop. This is determined according to the instant speed $(v 1)$ of the train and the permitted speed $(v 2)$ which is decided based on the braking performance of the train and the transport distance from the location of the train at the beginning of this calculation interval to the next stop. If $v 1 \geq v 2$, the train brakes to decrease as soon as possible its speed to a comparatively small value which is able to ensure absolute safety of its stop in the next station. If $v 1<v 2$, the train coasts. Such a decision is made for each latter calculation interval till the train stops in security at the next station. This is according to the $v 1$ of the train in each of the latter calculation intervals and the $v 2$ determined based on not only the location of the train at the beginning of each latter calculation interval but also the braking performance of the train.

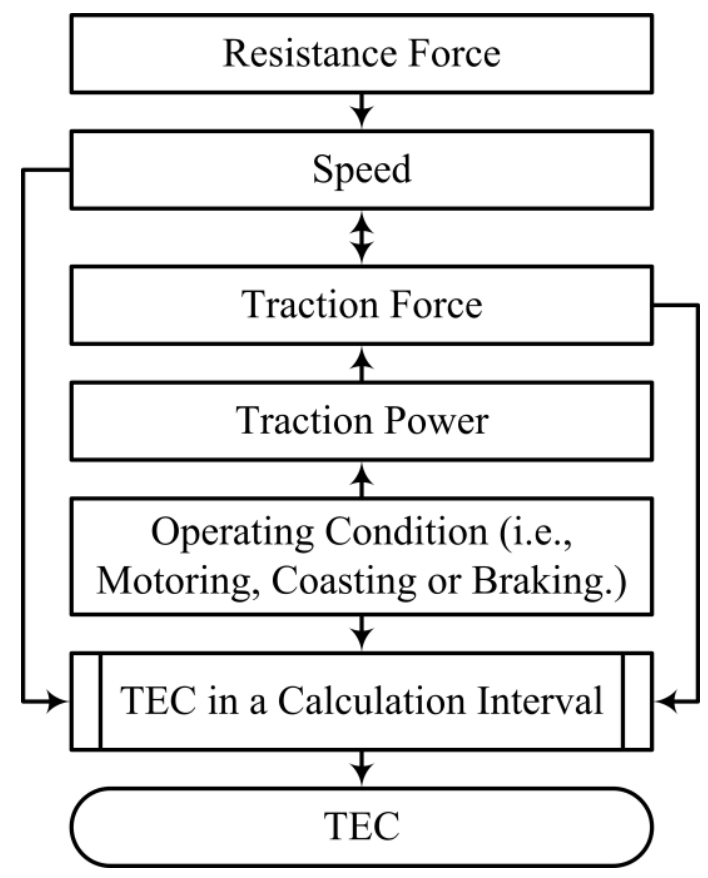

Figure 1. Framework of the Simulation Approach to Calculate the TEC

The traction force of the train utilizing a certain ratio, i.e., $r \%$, of its full traction power in a calculation interval is determined by both the instant speed and the operating condition of this train, as interpreted by equation (1). When the train is coasting or braking, its traction force is $0 \mathrm{~N}$.

$$
f_{k}^{r}=\left\{\begin{array}{l}
P_{k}^{r} / v_{k-1}^{p r}, \text { if }\left(v^{t m}-v_{k-1}^{p r}\right)>C^{t m} \text { or }\left(v_{k}^{u l}-v_{k-1}^{p r}\right)>C^{u l} \\
0, \text { if }\left(v^{t m}-v_{k-1}^{p r}\right) \leq C^{t m} \text { or }\left(v_{k}^{u l}-v_{k-1}^{p r}\right) \leq C^{u l}
\end{array}\right.
$$

Where,

$f_{k}^{r} \quad$ : Traction force of the train utilizing $r \%$ of its full traction power in the $k^{\text {th }}$ calculation interval, Unit: $\mathrm{N}$,

$P_{k}^{r} \quad$ : Traction power of the train utilizing $r \%$ of its full traction power in the $k^{\text {th }}$ 
calculation interval, Unit: W,

$v_{k-1}^{p r} \quad$ : Instant speed of the train utilizing $p r \%$ of its full traction power at the end of the $(k-1)^{\text {th }}$ calculation interval, Unit: $\mathrm{m} / \mathrm{s}$,

$v^{t m} \quad:$ Target speed of the train, Unit: $\mathrm{m} / \mathrm{s}$,

$v_{k}^{u l} \quad:$ Upper limit speed in the $k^{t h}$ calculation interval, which is equal to $v^{t m}$ when there is no requirement by the rail line, Unit: $\mathrm{m} / \mathrm{s}$,

$C^{t m} \quad$ : Permitted maximum difference between speed of the train and target speed, Unit: $\mathrm{m} / \mathrm{s}$, and

$C^{u l} \quad:$ Permitted maximum difference between speed of the train and upper limit speed which is equal to $C^{t m}$ when there is no requirement by the rail line, Unit: $\mathrm{m} / \mathrm{s}$.

As explained by equation (1) and equation (2), the instant speed of the train in a calculation interval is decided by the speed of the train at the end of the previous calculation interval, the traction force for the utilized proportion of its full traction power in this calculation interval, the target speed, the upper limit speed required by the rail line in this calculation interval, the mass of the train and the resistance force from air, rail line, etc., in this calculation interval.

$$
v_{k}^{r}=v_{k-1}^{p r}+\frac{f_{k}^{r}-f_{k}^{L}}{M} \times \Delta t
$$

Where,

$v_{k}^{r} \quad$ : Speed of the train utilizing $r \%$ of its full traction power at the end of the $k^{\text {th }}$ calculation interval, Unit: $\mathrm{m} / \mathrm{s}$,

$f_{k}^{L} \quad$ : Resistance force in the $k^{\text {th }}$ calculation interval, Unit: $\mathrm{N}$, which is measured by equation (3),

$M \quad:$ Mass of the train, Unit: $\mathrm{Kg}$, and

$\Delta t \quad$ : Equivalent length of the calculation intervals, i.e., $1.00 \mathrm{~s}$, in this work.

$$
f_{k}^{L}=\alpha_{0}+\alpha_{1} \times\left(v_{k-1}^{p r}\right)+\alpha_{2} \times\left(v_{k-1}^{p r}\right)^{2}+f_{k}^{S}
$$

Where,

$\alpha_{0}, \alpha_{1}, \alpha_{2}$ : Coefficients determined by the body streamline design of the locomotive, the friction between the wheels and the rail, etc., and

$f_{k}^{s} \quad:$ Resistance from the ramps, bends, etc., of the rail line in the $k^{\text {th }}$ calculation interval, Unit: N. Because of the afore-explained assumption of a hypothetically straight and smooth rail line, the special resistance force is $0 \mathrm{~N}$ in this study.

Various types of locomotives have different traction performances to overcome the resistance force in their traction processes on the same rail line for the same transport work and the same target speed at the expense of different traction energy consumption. The TECs of all the calculation intervals of the simulation work from the startup of the train at a station to its stop at another station are summed into the TEC of the trip between these two stops.

\section{Analysis of Traction Energy Cost Intensity}

The TEC per 10,000 t-km of a freight train is defined by equation (4) to evaluate its traction energy cost intensity. 


$$
e_{i j}^{v}=\frac{E_{i j}^{v}}{\left(\sum_{q=1}^{m}\left(C_{i j}^{v, q} \times R_{i j}^{v, q}\right)\right) \times D_{i j}^{v}}
$$

Where,

$e_{i j}^{v}:$ TEC per 10,000 t-km of the train with the target speed of $v$ from station $i$ to station $j$, Unit: kWh/10,000 t-km,

$E_{i j}^{v} \quad:$ TEC of the train with the target speed of $v$ from station $i$ to station $j$, Unit: $\mathrm{kWh}$,

tn : Total number of the railway cars composing the train,

$C_{i j}^{v, q}$ : Loading capacity of the qth railway car of the train with the target speed of $v$ from station $i$ to station $j$, Unit: $t$,

$R_{i j}^{v, q}:$ Utilization ratio of the loading capacity of the qth railway car of the train with the target speed of $v$ from station $i$ to station $j$, Unit: \%, and

$D_{i j}^{v}$ : Transport distance of the train with the target speed of $v$ from station $i$ to station $j$, Unit: 10,000 kilometers $(\mathrm{km})$.

Due to data limitation, the railway line studied in this research is hypothetically straight and smooth. The transport distance (Unit: $10,000 \mathrm{~km}$ ) from the $n^{\text {th }}$ stop $(S(n))$ to the $(n+1)^{\text {th }}$ stop $(S(n+1))(n=1,2, \ldots \ldots, 20)$ of this railway line in this research is interpreted by equation $(5)$.

$$
D_{S(n), S(n+1)}=5.00 \times 10^{-4} \times n
$$

Because the loading capacity of each railway freight wagon is usually required to be $100 \%$ utilized in China, the train studied in this work is fully loaded. The changes of the TECs per $10,000 \mathrm{t}-\mathrm{km}$ of the freight train hauled by respectively the SS1 and the SS4 with the increases of the target speeds between different neighboring stops are revealed in Figure 2 and Figure 3 correspondingly. It is found in both of these two figures that the TEC per 10,000 t-km is obviously increased with the decrease of the length of stop-spacing from about $20.00 \mathrm{~km}$ for the same target speed. Moreover, the increase of the TEC per 10,000 t-km with the improvement of the target speed is accelerated by the decrease of the transport distance between neighboring stops. Such acceleration continues till the inter-stop transport distance or the traction performance of the locomotive starts to prevent the train from achieving a relatively high target speed especially for a comparatively short stop-spacing. It is evidently shown in these two Figures that making stop-spacing shorter than $20.00 \mathrm{~km}$ ceases more early achievement of the target speed of a train and meanwhile more rapid increase of its TEC per $10,000 \mathrm{t}-\mathrm{km}$ with the improvement of the target speed. These trends could be approximately explained by equation (6) according to curve fitting studies. Furthermore, the effect of the decreasing transport time by improving the target speed will be much traded off by shortening the stop-spacing which in fact causes frequent starts and stops for the whole trip of a train. This has been ever proved by Lindgreen and Sorenson [17] and van Wee, et al., [30]. In contrast, changes of the inter-stop transport distances over $20.00 \mathrm{~km}$ have little effect on the TEC per 10,000 t-km.

$$
e_{i j}^{v}=\left(\alpha+\frac{20}{\beta \times D_{i j}^{v}}\right) \times v_{i j}^{a}+\lambda \ln \left(\frac{D_{i j}^{v}}{10000}\right)+\delta,(\alpha>1, \beta>2, \lambda<-5 \& \delta>50)
$$

Where $v_{i j}^{a}$ is the achieved maximum speed of the train with the target speed of $v$ from 
station $i$ to station $j$, and $\alpha, \beta, \lambda$ and $\delta$ are the constant parameters specifically determined by the (machinery) general traction performance of the applied locomotive.

It is revealed in Figure 2 that if the target speed of the train hauled by the SS1 is e.g., 70.00 $\mathrm{km} / \mathrm{h}$, the decrease of the length of stop-spacing from $20.00 \mathrm{~km}$ to $10.00 \mathrm{~km}$ additionally consumes approximately $50.00 \mathrm{kWh}$ per $10,000 \mathrm{t}-\mathrm{km}$. Because of the restriction of the traction performance of the SS1, the target speed of the train hauled by the SS1 cannot exceed $80.00 \mathrm{~km} / \mathrm{h}$. As a result, the TECs per $10,000 \mathrm{t}-\mathrm{km}$ become stable for all the transport distances between neighboring stops after the target speed reaches $80.00 \mathrm{~km} / \mathrm{h}$. In comparison, the relatively superior traction performance of the SS4 has no impact on the increase of the TECs per $10,000 \mathrm{t}-\mathrm{km}$ of the train with the improvement of the target speed for different inter-stop transport distances, as shown in Fig.3. The decrease of the inter-stop transport distance from $20.00 \mathrm{~km}$ to $10.00 \mathrm{~km}$ additionally consumes around $40.00 \mathrm{kWh}$ per 10,000 $\mathrm{t}-\mathrm{km}$ when the target speed of the train hauled by the SS4 is $70.00 \mathrm{~km} / \mathrm{h}$.

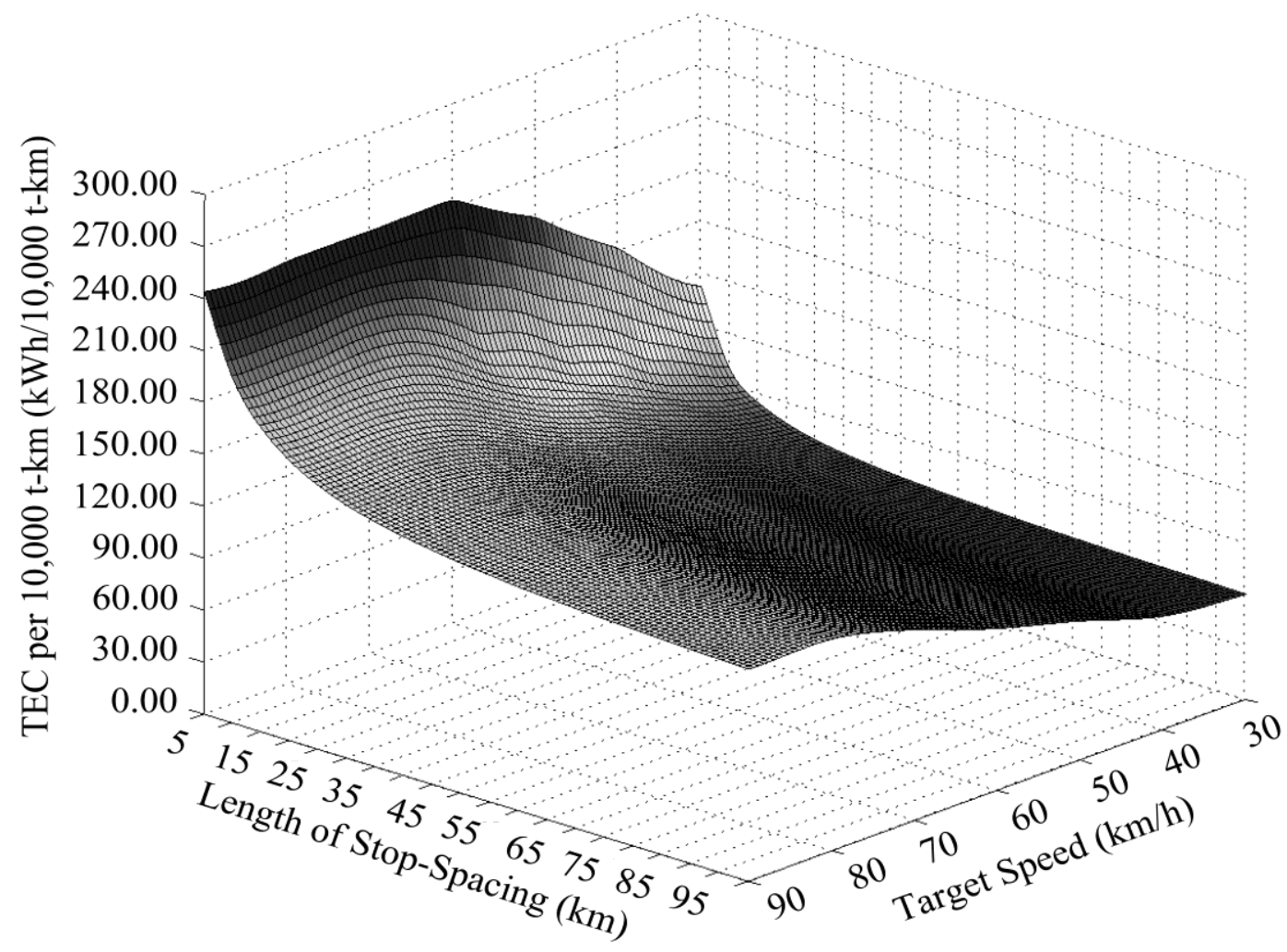

Figure 2. TECs of the Freight Train Hauled by the SS1 


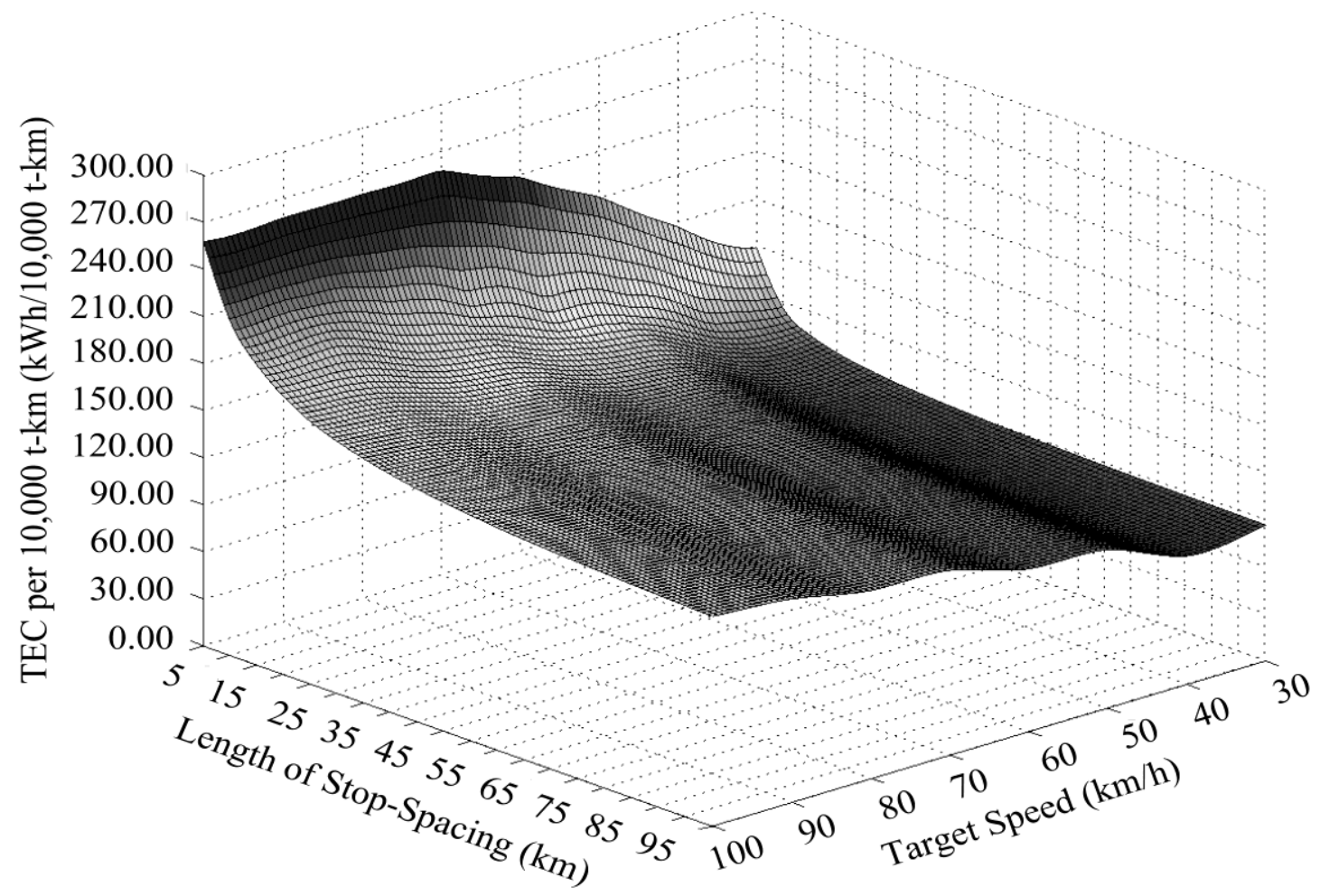

Figure 3. TECs of the Freight Train Hauled by the SS4

\section{Conclusions}

According to computer-aided simulations of the transports of a typically formed Chinese freight train, this research tries to analyze the exact integrated effect of the inter-stop transport distance together with the target speed of the train on its TEC intensity. It is empirically confirmed that the TEC per unit transport of a freight train with an unchanged utilization ratio of its loading capacity increases apparently in an enlarging scale with the decrease of the length of stop-spacing from about $20.00 \mathrm{~km}$ for the same target speed. On the contrary, the increase of the TEC per unit transport with the improvement of the target speed of the train is slightly decelerated by the increase of the transport distance between neighboring stops. Therefore, the inter-stop transport distance of a freight train had better be no shorter than $20.00 \mathrm{~km}$. It is suggested that the railway freight transport work should organize heavy load trains in view of their inter-stop transport distances, energy-saving target speeds, etc., in a comprehensive manner. Meanwhile, applying locomotives with suitable traction performances is also very important. In addition, in the transport operation of a railway network, various requirements to the transport time of different trains and so on should also be considered for the decrease of their general TEC intensity in an integrated way.

Only the transports of a typically formed freight train hauled by respectively two major types of the freight locomotives in China on a hypothetically straight and smooth rail line are analyzed in this work. The impacts of more factors such as the track alignments, train formation, etc., on the traction energy cost intensity should 
also be studied together from a more comprehensive viewpoint in the future research to further validate the conclusions of this study.

\section{Acknowledgments}

This research is supported by Program for New Century Excellent Talents in University (NCET-13-0655), National Basic Research Program of China (2012CB725406) and National Natural Science Foundation of China (71201006; 71131001).

\section{References}

[1] "National Bureau of Statistics of China", China Statistical Yearbook 2011. Beijing: China Statistics Press, (2011).

[2] Q. Li and Y. Mao, "China's transportation and its energy use”, Energy for Sustainable Development, vol. 5, no. 4, (2011), pp. 92-99.

[3] J. Xi and G. Q. Chen, "Energy analysis of energy utilization in the transportation sector in China", Energy Policy, vol. 34, no. 14, (2006), pp. 1709-1719.

[4] J. He, W. Wu and Y. Xu, "Energy consumption of locomotives in China railways during (1975)-(2007)", Journal of Transportation Systems Engineering and Information Technology, vol. 10, no. 5, (2010), pp. 22-27.

[5] R. A. Uher, N. Sathi and A. Sathi, "Traction energy cost reduction of the WMATA Metrorail System", IEEE Transactions on Industry Applications, vol. 20, no. 3, (1984), pp. 472-483.

[6] E. V. Hoyt and R. R. Levary, "Assessing the effects of several variables on freight train fuel consumption and performance using a train performance simulator”, Transportation Research Part A: General, vol. 24, no. 2, (1990), pp. 99-112.

[7] R. Liu and I. M. Golovitcher, "Energy-efficient operation of rail vehicles", Transportation Research Part A: Policy and Practice, vol. 37, no. 10, (2003), pp. 917-932.

[8] Y. Huang and Q. Qian, "Research on improving quality of electricity energy in train's traction", Control and Decision, vol. 25, no. 10, (2010), pp.1575-1579.

[9] A. Chui, K. K. Li and P. K. Lau, Traction Energy Management in KCR”, IEE Conference Publication, vol. 1, no. 388, (1993), pp. 202-208.

[10] P. Lukaszewicz, "Energy Consumption and Running Time for Trains: Modelling of Running Resistance and Driver Behavior Based on Full Scale Testing [Doctoral Dissertation]", Stockholm: Royal Institute of Technology, (2001).

[11] A. R. Miller, J. Peters, B. E. Smith and O. A. Velev, "Analysis of fuel cell hybrid locomotives", Journal of Power Sources, vol. 157, no. 2, (2006), pp. 855-861.

[12] Y. V. Bocharnikov, S. Hillmansen, A. M. Tobias, C. J. Goodman and C. Roberts, "Optimal driving strategy for traction energy saving on DC suburban railways", IET Electric Power Applications, vol. 1, no. 5, (2007), pp. 675-682.

[13] I. López, J. Rodríguez, J. M. Burón and A. García, "A methodology for evaluating environmental impacts of railway freight transportation policies”, Energy Policy, vol. 37, no. 12, (2009), pp. 5393-5398.

[14] K. Kim and S. Chien, "Simulation-based analysis of train controls under various track alignments", Journal of Transportation Engineering, vol. 136, no. 11, (2010), pp. 937-948.

[15] K. Kim and S. Chien, "Optimal train operation for minimum energy consumption considering track alignment, speed limit, and schedule adherence", Journal of Transportation Engineering, vol. 137, no. 9, (2011), pp. 665-673.

[16] "Institut für Energieund Umweltforschung Heidelberg GmbH Energy Savings by Light-Weighting (Final Report)", Heidelberg: International Aluminum Institute, (2003).

[17] E. Lindgreen, S. C. Sorenson, "Simulation of Energy Consumption and Emissions from Rail Traffic Evaluation (Report No: MEK-ET-2005-04)”, Lyngby: Technical University of Denmark. (2005).

[18] S. Lu, S. Hillmansen and C. Roberts, "A power-management strategy for multiple-unit railroad vehicles", IEEE Transactions on Vehicular Technology, vol. 60, no. 2, (2011), pp. 406-420.

[19] X. Feng, L. Feng, K. Wu, H. Liu and Q. Sun, "Evaluating target speeds of passenger trains in China for energy saving in the effect of different formation scales and traction capacities", International Journal of Electrical Power \& Energy Systems, vol. 42, no. 1, (2012), pp. 621-626.

[20] F. Ciccarelli, D. Iannuzzi and P. Tricoli, "Control of metro-trains equipped with onboard supercapacitors for energy saving and reduction of power peak demand", Transportation Research Part C: Emerging Technologies, vol. 24, (2012), pp. 36-49. 
[21] R. Teymourfar, B. Asaei, H. Iman-Eini and R. Nejatifard, "Stationary super-capacitor energy storage system to save regenerative braking energy in a metro line", Energy Conversion and Management, vol. 56, (2012), pp. 206-214.

[22] S. Acikbas and M. T. Soylemez, "Coasting point optimisation for mass rail transit lines using artificial neural networks and genetic algorithms", IET Electric Power Applications, vol. 2, no. 3, (2008), pp. 172-182.

[23] L. Yang, K. Li, Z. Gao and X. Li, Optimizing trains movement on a railway network", Omega, vol. 40, no. 5, (2012), pp. 619-633.

[24] "European Communities Transport Research Fourth Framework Programme Strategic Research: DG-VII 99: Meet Methodology for Calculating Transport Emissions and Energy Consumption”, Luxembourg: Office for Official Publications of the European Communities, (1999).

[25] J. Yan and M. Fu, "Automotive Engineering ( $3^{\text {rd }}$ Edition)", Beijing: China Railway Publishing House, (2008).

[26] Z. Yang, X. Huang, S. Wu and H. Peng, "Traction Technology for Chinese Railways", 2010 International Power Electronics Conference (CD-ROM)", IEEE (Institute of Electrical and Electronics Engineers), Sapporo, (2010), pp. 2842-2848.

[27] X. Feng, "Optimization of target speeds of high-speed railway trains for traction energy saving and transport efficiency improvement", Energy Policy, vol. 39, no. 12, (2011), pp. 7658-7665.

[28] H. I. Andrews, "Railway Traction: The Principles of Mechanical and Electrical Railway Traction", Studies in Mechanical Engineering, New York: Elsevier, vol. 5, (1986).

[29] B. Mao, X. Li and H. Niu, "Train Performance Calculation and Design", Beijing: Communication Press, China, (2008).

[30] B. Van Wee, R. Van Den Brink and H. Nijland, "Environmental impacts of high- speed rail links in cost-benefit analyses: A case study of the Dutch Zuider Zee line", Transportation Research Part D: Transport and Environment, vol. 8, no. 4, (2003), pp. 299-314. 
International Journal of $u$ - and e- Service, Science and Technology Vol.7, No.3 (2014) 